\title{
Novos registros de Pboetalia pallida (Brunner, 1865) para o Brasil e considerações sobre a variação cromática da espécie (Blattaria, Blaberidae, Blaberinae).
}

\author{
Sonia Maria LOPES ${ }^{1}$; Edivar Heeren de OLIVEIRA ${ }^{1}$; Maria Carmosina de ARAÚJO²
}

\section{RESUMO}

Apresenta-se um novo registro de Phoetalia pallida (Brunner, 1865) para o Brasil, nas regiões norte, nordeste e centrooeste, é descrita, pela primeira vez, a genitália da espécie e é analisada a variação cromática de pronoto e cabeça, entre as localidades assinaladas.

PALAVRAS-CHAVE

Blattaria, Phoetalia pallida, Taxonomia, variação cromática.

\section{New records of Phoetalia pallida (Brunner, 1865) from Brazil and considerations about the chromatic variation of the species (Blattaria, Blaberidae, Blaberinae).}

\begin{abstract}
A new record of Phoetalia pallida (Brunner, 1865) from Brazil is presented, in the north, northeast and central-west areas, the genitalia of the species is described for the first time, and the chromatic variation of pronotum and head, is analysed among specimens of the marked locations.
\end{abstract}

\section{KEY WORDS}

Blattaria, Phoetalia pallida, Taxonomy, chromatic variation.

O adulto de Phoetalia Shelford, 1910 é caracterizado por possuir pronoto reto na base, vértice bastante evidenciado, tégminas com veias transversais pouco nítidas e fêmur I na face ântero-ventral com 3 a 5 espinhos pequenos, porém robustos, próximos à base, seguidos de uma fileira de espinhos finos muito próximos uns aos outros.

O gênero Phoetalia Shelford, 1910 foi considerado por Rehn (1928) similar a Litopeltis Hebard, 1920. Roth (1970) com base no estudo da genitália masculina, discordou de Princis (1960) e de Mckittrick (1964) e retirou o gênero Phoetalia da subfamília Epilamprinae e colocou na subfamília Blaberinae, com base na presença de capuz de espinhos (prepúcio) em torno do ápice do esclerito mediano (L2d).

Compõe o gênero duas espécies: Pboetalia circunvagans (Burmeister, 1838) e Pboetalia pallida (Brunner, 1865), a qual neste trabalho é enfocada.

Brunner (1865) assinalou a espécie no Brasil sem registrar o local de coleta.
Neste trabalho são feitos três novos registros de ocorrência para a espécie em Estados do Brasil (Mato Grosso, Pará e Bahia), e é ilustrada a variação cromática de pronoto e cabeça dentro da espécie.

Foram utilizadas abreviaturas para os locais de depósito dos exemplares pertencentes ao gênero: ANSP (Academy of Natural Sciences of Philadelphia, Estados Unidos da América do Norte); MNRJ (Museu Nacional do Rio de Janeiro, Rio de Janeiro, Brasil); INPA (Instituto Nacional de Pesquisas da Amazônia, Manaus, Brasil).

Phoetalia pallida apresenta coloração castanho-clara brilhosa; pronoto castanho com mancha centro-basal castanho-escura, mais larga na base, estreitando-se para o ápice (Figs 2, 4, 6 e 8); cabeça com olhos, vértice, espaço interocular, fronte e base do clípeo castanho-escuros (Figs. 1, 3, 5 e 7); antenas castanhas, estas com os artículos a partir do nono tomentosos e foscos; ocelos bem evidenciados em amarelo-claro; ápice dorsal de cada artículo dos palpos

\footnotetext{
${ }^{1}$ Departamento de Entomologia, Museu Nacional, UFRJ, Quinta da Boa Vista, São Cristóvão, RJ, Brasil, CEP 20940-040, sonialf@acd.ufrj.br ${ }^{2}$ Instituto Nacional de Pesquisas da Amazônia, Manaus, AM, Brasil CEP 69011-970, carmo@inpa.gov.br
} 


\section{ACTA \\ AMAZONICA}

NOVOS REGISTROS DE Phoetalia pallida (BRUNNER, 1865) PARA O BRASIL E CONSIDERAÇÕES SOBRE A VARIAÇÃO CROMÁTICA DA ESPÉCIE (BLATTARIA, BLABERIDAE, BLABERINAE) maxilares amarelo esbranquiçado. Pernas castanhas, com o entorno da base das coxas, espinhos das tíbias e unhas castanho mais escuros; arólios e pulvilos esbranquiçados. Tégminas com veias na metade basal, com coloração mais intensa, clareando em direção ao ápice; tronco inicial de todas as veias mais pigmentado.

Nove exemplares dessas regiões foram examinados e apresentaram variação na coloração do pronoto, e na cabeça em relação à distância interocular. Quanto a genitália do macho, foi verificada semelhança entre elas: no esclerito mediano (L2vm) apresentam o capuz desenvolvido, com espinhos pouco afilados sendo o ápice (L2d) em forma de um pé afilado com a borda realçada; falômero direito (R2) com ápice foliáceo com reentrância sub-apical e falômero esquerdo (L1) esclerotinizado medianamente. A genitália do macho descrita acima foi ilustrada em Roth (1970).

Nas espécies da Bahia a coloração geral é mais intensa e o espaço interocular é mais alargado (Figs. 1 e 3), enquanto que nas espécies de Mato Grosso o espaço interocular é

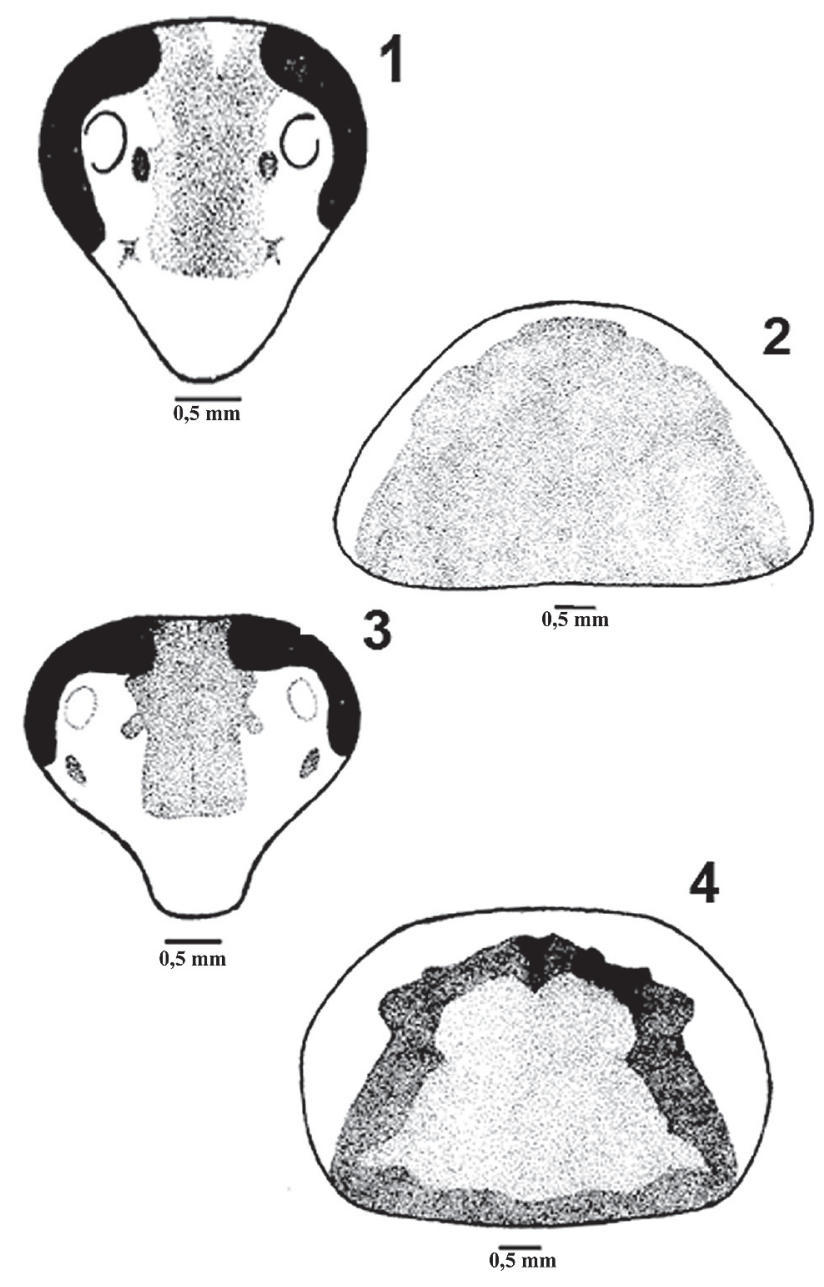

Figuras 1 a 4 - Phoetalia pallida (Brunner, 1865) (macho). Brasil: Bahia; 1, cabeça; 2, pronoto; 3, cabeça; 4, pronoto. mais estreito (Figs. 5 e 7). O material do Pará é uma fêmea.

Material-tipo: Macho, CUBA: Martinica (ANSP).

Dimensões (mm). Macho. Comprimento total 20,0-23,0; comprimento do pronoto 3,5-4,5; largura 5,5-6,5; comprimento da tégmina 16,0-19,0; largura 5,0-6,0.

Material examinado: BRASIL: Mato Grosso, Sinop, 12³1'S e 55037'W, BR 163 km 500-600, 350m altitude, IX.1974, Alvarenga \& Roppa cols. (5 machos) (MNRJ); Vera, X.1973, Alvarenga \& Roppa cols. (1 macho) (MNRJ); Babia, Encruzilhada (1 macho) (MNRJ); Itiuba, Est. Monte Santo (1 macho) (em bromélia) (MNRJ); Pará, Tucuruí, Ilha Chorona, 17.VIII. 1980, Nunes de Mello col. (1 fêmea) no 5.646 (INPA).

Registros Geográficos: Estados Unidos da América do Norte (Flórida), México, Guatemala, Cuba (Martinica), Jamaica (Montego Bay, Point Antonio), Costa Rica (San José), Porto Rico (Isla de Mona, Isla Viesques), Montserrat, Hispaniola (República Dominicana, Haiti), Equador (Ilhas Galápagos), Venezuela, Brasil (Mato Grosso, Pará, Bahia).

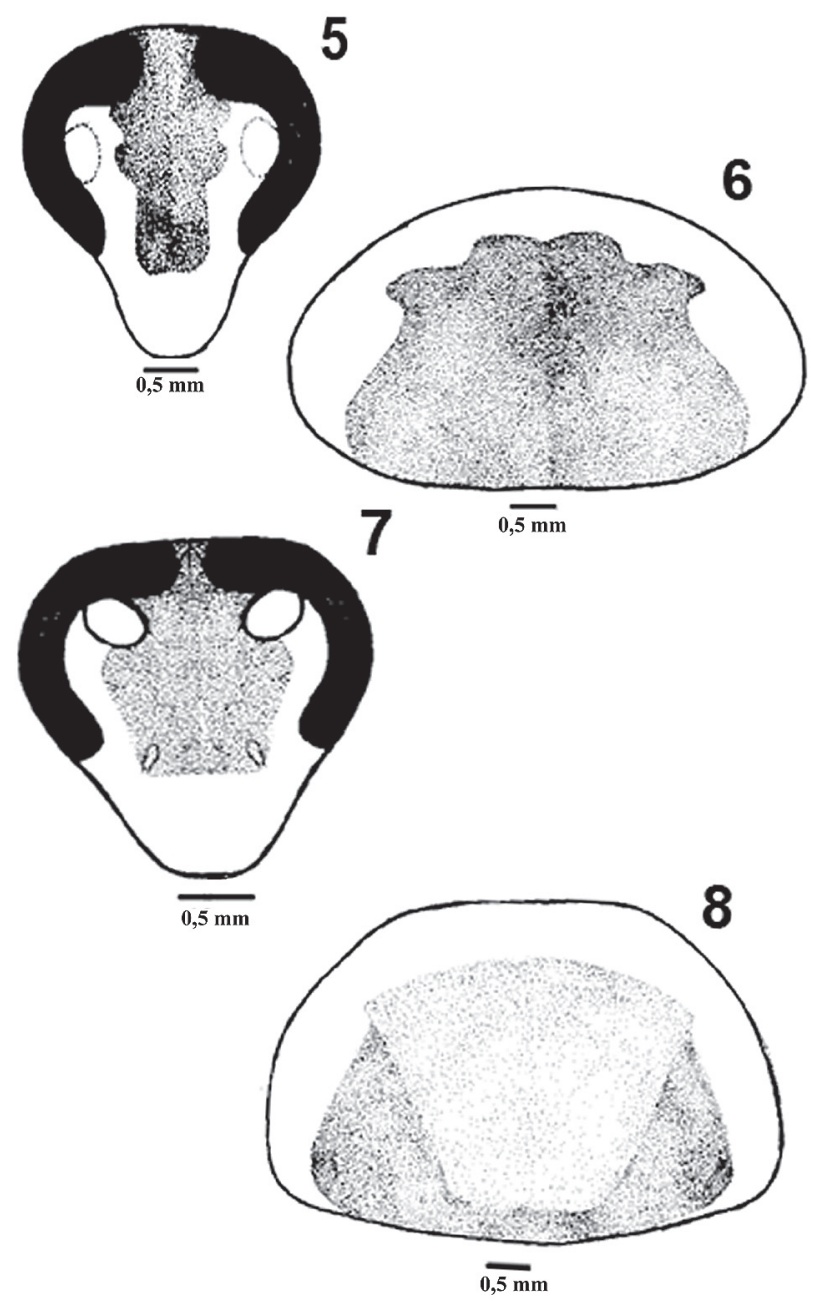

Figuras 5 a 8 - Phoetalia pallida (Brunner, 1865) (macho). Brasil: Mato Grosso: 5, cabeça; 6, pronoto; 7 , cabeça; 8 , pronoto. 


\section{ACTA \\ AMAZONICA}

NOVOS REGISTROS DE Phoetalia pallida (BRUNNER, 1865) PARA O BRASIL E CONSIDERAÇÕES SOBRE A VARIAÇÃO CROMÁTICA DA ESPÉCIE (BLATTARIA, BLABERIDAE, BLABERINAE)

\section{AGRADECIMENTOS}

ÀDra. Janira Martins Costa, professora do Museu Nacional, pelo apoio técnico. Ao Dr. José Albertino Rafael, pesquisador do INPA, pelo empréstimo do material para estudo.

\section{BIBLIOGRAFIA CITADA}

Brunner, W. C. 1865. Nouveau systeme des Blattaires. Societé I.R. de Zoologie et Botanique, Vienna. xi+426pp.

Mckittrick, F.A. 1964. Evolutionary studies of cockroaches. Cornell University Agricultural Experiment Station, 389: 1-197.
Princis, K. 1960. Zur Systematik der Blattarien. Eos Revista Española de Entomologia, 36(4): 427-449.

Rehn, J. A. G. 1928. New or little known neotropical Blattidae (Orthoptera). Number one. Transaction American Entomological Society of Philadelphia 54: 125-195, 4 pls.

Roth, L. M. 1970. The male genitalia of Blattaria. IV. Blaberidae: Blaberinae. Psyche 77(3): 308-342.

RECEBIDO EM 12/11/2003

ACEITO EM 13/05/2004 
